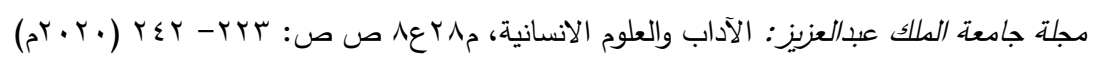

\title{
وصف الأطلال في الثعر العباسي قصيدة " سلام عليكم " أنموذجا \\ (دراسة نقدية)
}

\author{
د. حمدة بنت مشارك الرويلي \\ الأستاذ المساعد بقسم اللغة العربية تخصص أدب قديم \\ جامعة الحدود الشمالية-كلية التربية والآداب \\ قسم اللغتة العربية
}

مستخلص. أجاد البحتري في الفنون الثعرية المتنوعة في العصر العباسي لا سيما فن الوصف، الذي ظهرت براعته وقدرته فيه أكثر من بقية الفنون، فقد كان من أشهر شعراء الوصف لا سيما في وصف الطئ الطبيعة التي عشقها وحاول توظيفها في أغراضه الثعرية المختلفة، لذلك وقع اختياري في هذه الدراسة على قصيدة "سلام عليكم" التي تمثل جانب من هذه الطبيعة، بهدف إلقاء الضوه على نص يعد من النصوص التي تضمنت مشهدا من مشاهد صراع البحتري مع الذئب، إذ تحاول هذه الدراسة الوقوف على السمات الفنية في النص الشعري وكيفية التعامل معه

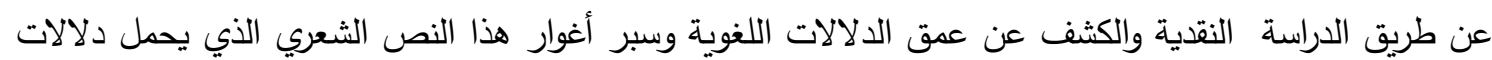
الكلمات المفتاحية: سلام عليكم-المقدمة الطللية-ملامح التجديد-وصف الطبيعة.

لأن صياغة النص تتأسس على بنية فهمه القائمة بدورها على متغيرات الدراسة التي تزيح ثوابته وتكشف مكنوناته، ومن هنا يتراءى التأويل شرطا لإضاءة نصوص الأطلال في الشعر العباسي ويتضح ذلك من خلال ما جاء في قصيدة البحتري التي مطلعها: "سلامُ عَليكُم"، كما لابد لنا من الوقوف

\section{المقدمة}

الحمد لله رب العالمين، والصلاة والسلام على أشرف المرسلين، سيدنا محمد وعلى آله وأصحابه والتابعين بإحسان إلى يوم الدين، أما بعد: تقوم فكرة هذا الموضوع على تحليل النص الشعري من خلال تحريك التراكم المعرفي وإثارة التساؤلات؛ 


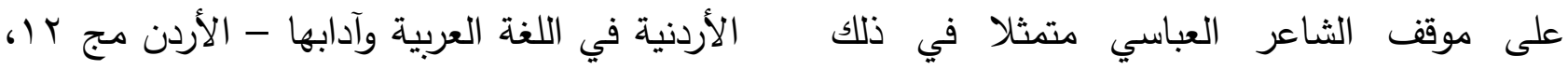

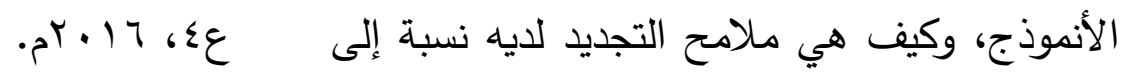

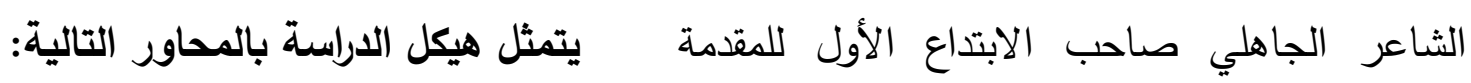

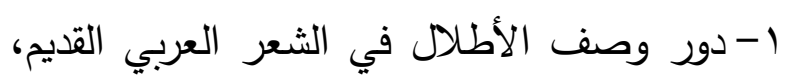
ومكانة البحتري عند النقاد. الطللية الممهدة للاخول في غرضده الثعري، وكيف كانت ملامح التجديد وتجلياته لدى البحتري في فرهدي

r- اتجاهات البحتري في شعره من خلال قصيدة " الأسلوب والدلالة، كما يعوزنا في هذا الدقام اللجوء

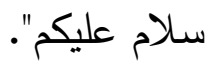
إلى منهج الموازنة بين كل من المقدمة الطللية لدى r-صورة الذئب بين البحتري والمرقش الأكبر وعلاقتها بالأطلال. الثاعر الجاهلي، والثاعر العباسي، وذلك من خلال تبني قوانين تحليل الخطاب التي تتعامل مع النص مص

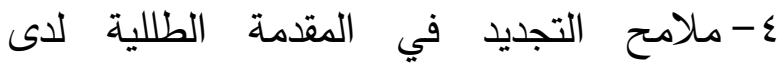
الشعري بوصفه بنية لسانية وفكرية، تحيلنا إلى ليع لئلين

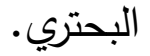
مرجعيات ثقافية؛ لتكثف من خلال ذلك كله وأخيرا الحمد الله رب العالمين. الحمولات الدلالية، التي تساعد على استطاق النص أولا: دور وصف الأطلال في الثعر العربي القديم، ومكانة البحتري عند النقاد: برزت ملامح المقدمة الطللية في القصيدة عند الشعراء الجاهليين منذ القدم، فقد استهلوا قصائدهم بالوقوف على الأطلال، وذكر الديار والدمن المتبقية الشعري ذاته، وإفساح أكبر مساحة من التحليل؛ لأجل الاخول إلى المقدمات الطللية للعصر العباسي داسي هني من خلال أنموذج البحتري، وذلك للوقوف على لـى لئى السمات الأسلوبية لهذا الفن الشعري.

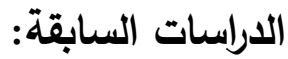
من آثار ديار المحبوبة، ومن الصور التي تتردد في لهدي الهقدمة الطللية أن يبدأ الثاعر الجاهلي قصيدته بذكر الديار التي عفت أو درست ولم يتبق منها إلا

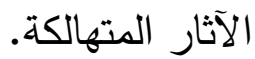
وقصيدة البحتري "سلام عليكم لا وفاء ولا عهد" تعد بشكل أو آخر استمرارا لتلك القصائد الجاهلية التي تتعدد الموضوعات فيها، وتتتوع عناصرها، فعنصر الأطلال يسير في القصيدة على نهج القصيدة الجاهلية، ويرتبط بالغزل والمرأة والوصف، والقصيدة 
الأماكن، والحيوانات التي تعيش في تلك الديار،

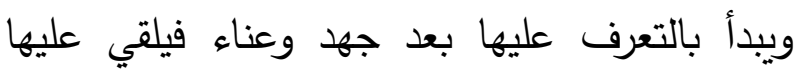
التحية، وكأن هذه التحية موجهة إلى محبوبته التي لئي جاءت رمزا للدلالة على الوفاء بالعهود بين القبائل المتحاربة عندما تصالحوا، وهذا رمز جيد يلخص الحالة النفسية للشاعر المطمئنة نتيجة هذا الوفاء الذي كان سببا في استمرار تلك الحياة، فجاءت

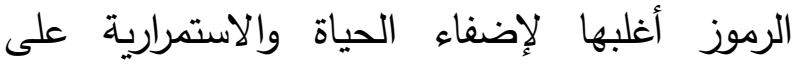
الطلل فيقول في مطلعها:

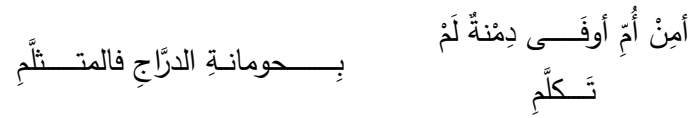

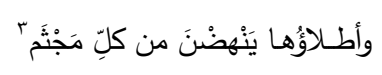

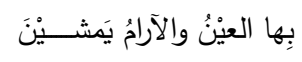
خلفة

يظهر أمامنا في البيتين السابقين مجموعة من تمان الصور لذلك الطلل "وهي ترتبط بحالة تذكر يعيشها

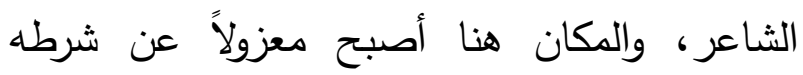
الإنساني، ذلك أنه لم يعد سوى بقايا آثار لم تدرس هن

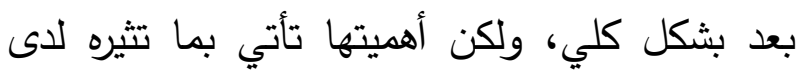
الثاعر ثم لاى المتلقي من ذكرى إنسانية ينقلها إلينا الثاعر بالتدريج لتصبح تجربته الخاصة في المكان

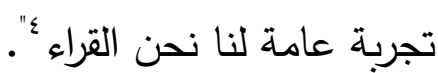
كما ذكر عبيد بن الأبرص الديار الدارسة، والأمكنة

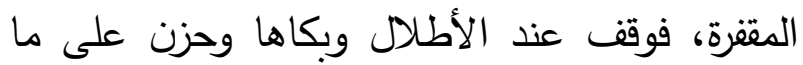
تبقى منها بصدق فنقل لنا تجربة صادقة تعبر عن واقع حقيقي لتلك الحياة التي يعيشها، فهذه الوقفة

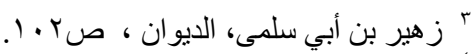

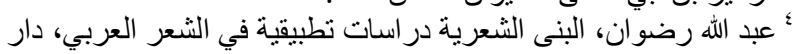

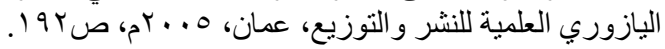

التي بين أيدينا جاءت في "وصف الذئب"، مما جعل

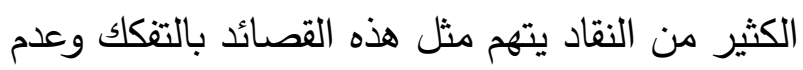

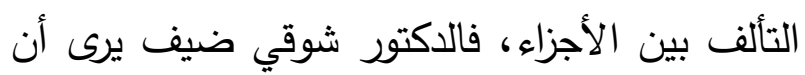

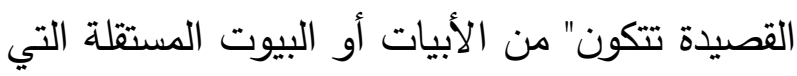

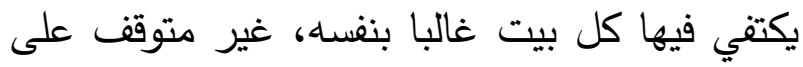

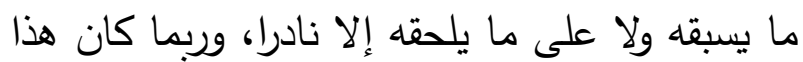
هو السبب الحقيقي في أن القصيدة الطويلة لا تلم بموضوع واحد يرتبط به الثاعر، بل تجمع طائفة من الموضوعات والعواطف لا تظهر بينها صلة ولا

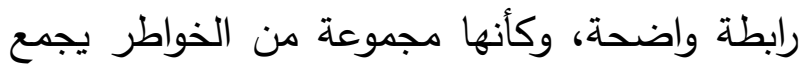

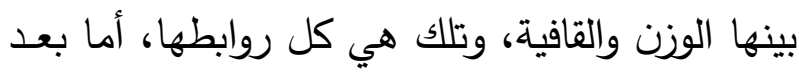
ذلك فهي مفككة، لأن صاحبها لا يطيل المكث

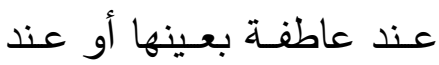

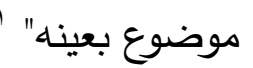
فها هو الثاعر زهير بن أبي سلمى يذكر الديار في

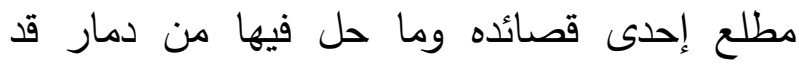
تسبب في إثارة دهشته وحيرته، من خلال سؤال يبدأه بالاستفهام الانكاري الذي يشير إلى جهله بتلك الديار ، ثم يجيب على نفسه فيقول:

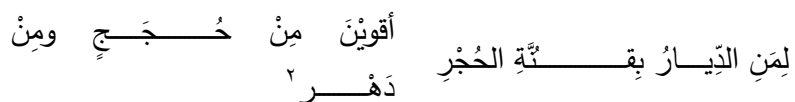
ونجده أيضا في مقدمة بعض قصائده يتجه إلى الغزل البدوي القح، فيبدأ أبياته الغزلية الرمزية ببكاء

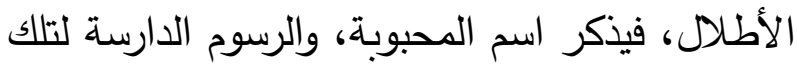

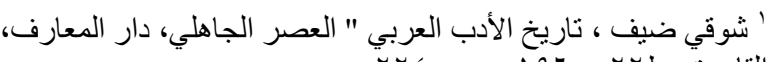

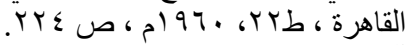

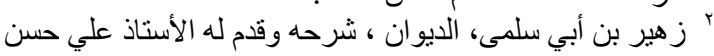

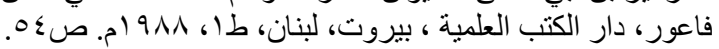




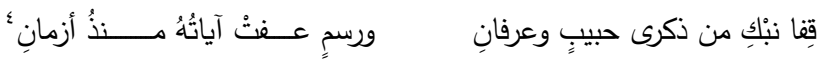
وشاعرنا البحتري هو أبو عبادة الوليد بن عبيد الله يحيى بن عبيد ابن شملال بن جابر بن سلمة بن مسهر بن الحارث بن خشيم، طائي الأب شيباني الأم، ولد سنة ع • r هـ، إلى الثمال الثرقي من حلب على الطريق المؤدية إلى الفرات، وقد غلب عليه لقب البحتري نسبة إلى عشيرته الطائية "بحتر"ه

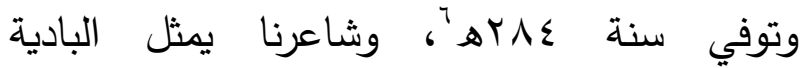
والحاضرة معا: "فهو ابن البادية ولا وترعرع في كنفها، فمنحته خصائصها، وزودته بطبائعها، ورفدته

بتقاليدها وغذته بمأثورها، وأكسبته فصاحتها" . وقد قيل فيه: "شاعر البداوة والحضارة، ورجل النقل والتأمل، ورجل البناء الوصفي الفني، ورجل الصناعة البديعة الجميلة، وكان أخيرا شاعر الغنة الساحرة،

$$
\text { الذي أراد أن يشعر فغنى" ". }
$$

أما قصيدة "سلام عليكم" فقد وصفت بأنها من أروع القصائد في وصف الحياة إذ قيل عنها: "إنها صورة رائعة من صور الصراع النفسي من أجل الحياة استطاع فيها البحتري على رغم حداثة سنه حين قال هذه القصيدة أن يوفق بين تنسيق أجزائها، واستطاع

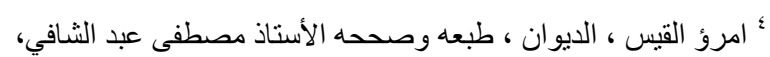

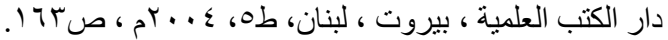

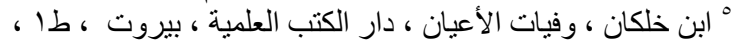

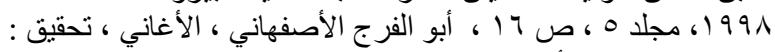

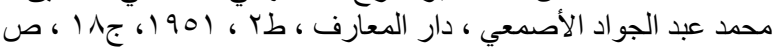
' ياقوت الحموي ، معجم الأدباء ، دار المأمون ، القاهرة ، ج9 1 ، ص

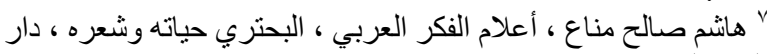

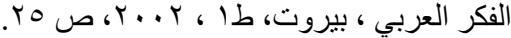

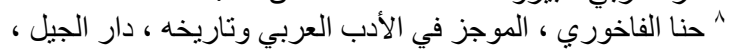

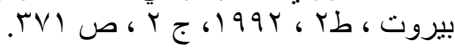

الطللية التي تستهل فيها القصائد ماهي إلا رموزا تعبر تعبيرا صادقا عن واقع حقيقي ولا تكاد تخلو منها قصيدة من قصائد الثعر القديم، فها هو عبيد بن الأبرص يجسد لنا بصدق ذلك الواقع فيقول:

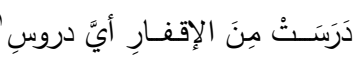

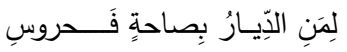
ومن الشعراء الذين بكوا الديار وسفحت دموعهم عندما وقفوا بتلك الأطلال، النابغة الذبياني الذي كان للوقفة الطللية في أبياته أثر نفسي عميق يجسد حزنه الشديد وألمه بسبب رحيل أحبته، وتبدل أحوال تلك الديار فيقولِ:

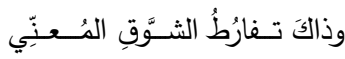
وقفْتُ بِها القلوصَ على اكتئَابٍ كأنَّ مفــْنَهُنَّ غـروبُ شَــنِّن

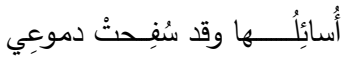
ونراه أيضا في صورة أخرى يعبر عن إحساسه الصادق وحزنه الشديد في وقت الغروب، فيسأل الديار عن أهلها بحسرة وألم خاصة أنها لم تجيب على ذلك السؤال، ثم يعترف بعدم وجود أحد حتى يجيبه، فرسم لنا صورة صادقة لذلك الواقع الذي كان يعيش فيه، ويتخذ من هذه المقدمة ستارا؛ ليعبر عما يختلج في نفسه من آثار نفسية بسبب غضب الملك نعمان عليه فيقول :

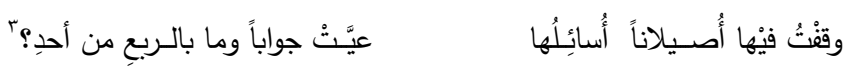
وهناك من يبدأ قصيدته الطللية بمناجاة أصحابه؛ ليستدعي معهم تلك الذكريات، وليشاركوه في ذلك المصاب كقولِ امرِيُ القيسِ:

$$
\begin{aligned}
& \text { 'عبيد بن الأبرص، الديون ، تحقيق حسين نصار ، شركة ومطبعة البابي }
\end{aligned}
$$

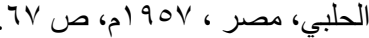

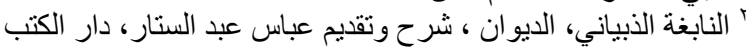

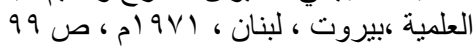

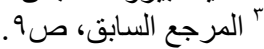


تفعل، مع جودة السبك وقرب المأتى، والقول في هذا قولهم، وإليه أذهب" مودة، والبحتري كما يرى الآمدي صاحب ذوق محافظ تقليدي يميل إلى أشعار القدماء.

ثانيا: اتجاهات البحتري في شعره من خلال قصيدة

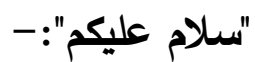

جاءت هذه القصيدة في أربعة مواضيع وهي:

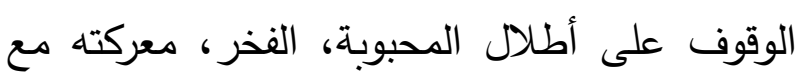

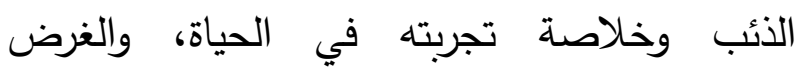
الأساسي من هذه القصيدة يتمثل في وصف الذئب، وقد وضح الدكتور زكريا النوتي أقسام القصيدة بقوله: "هذه القصيدة تتألف من عدة أقسام: غزل، التحريا فخر ، وصف الذئب، مذهبه في الحياة، والموضوع الأساسي في القصيدة هو الذئب، الذئاب البشرية والذئب الوحشي، فالثاعر قام لقصيدته بنسيب والنسيب له علاقة قوية بسائر أبيات القصيدة، إنه

$$
\text { نسيب حزين بائس" و لـ }
$$

وتتثكل القصيدة موضوع الدراسة من ثلاثة مقاطع باتئ هي: المقطع الأول الذي يصف فيه الثاعر محبوبته ويتمثل في الأبيات (1-7)، والمقطع الثاني الذي لأي لهي يتحدث عن شجاعته وقوته وجرأته والفخر بنفسه ويتمثل في الأبيات (v- 1 (1)، والمقطع الثالث الذي وجني يصف مشهد الذئب والصراع الذي دار بينهما ويتمثل

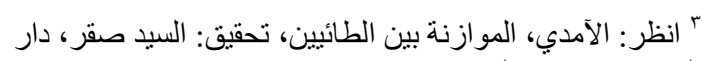

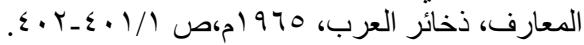

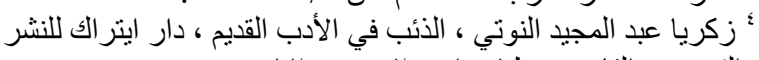

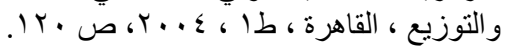

كذلك أن يعبر عن أحاسيسه الباطنية بما يكثف عن

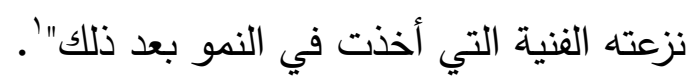

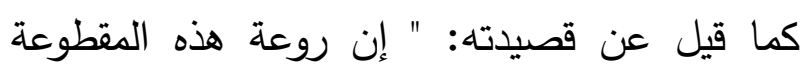
تكمن في طرافـتها، لقلة من حذا حذوها من الثعراء، وتتجلى المقدرة

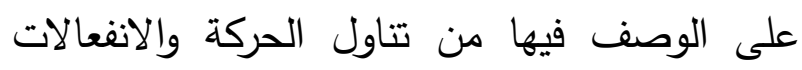
التي تتبعها بالتفصيل حتى كأن الثاعر فيها رسام والكلمات في فمه ريشته وألوانه المعبرة، كما أنه كان موفقا أيما توفيق في انتقاء الألفاظ التي تتناسب وموضوع القصيدة وتخدم ما رمى إليه من معان بكل

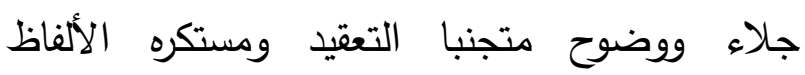
ووحشي الكلام وغريب الاستعارات، كما تجلت مقدرته في اختياره لحروف الألفاظ فجاءت أصواتها

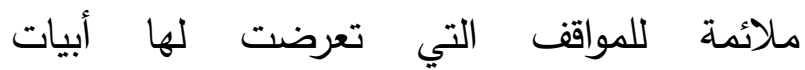
المقطوعة"'. التي تكشف عن العلاقة الممتدة بين الثاعر وهذا العالم العدواني المتوحش من خلال وصفه للأطلال. وكان أغلب النقاد يؤثرون طريقة البحتري التي لم

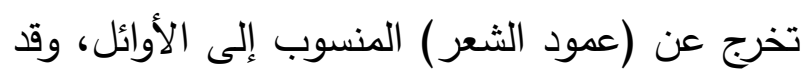

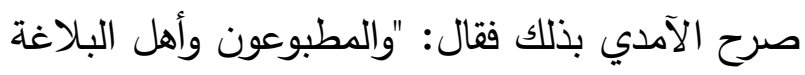
لا يكون الفضل عندهم من جهة استقصاء المعاني

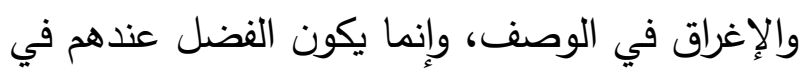
الإلمام بالمعاني وأخذ العفو منها كما كانت الأوائل

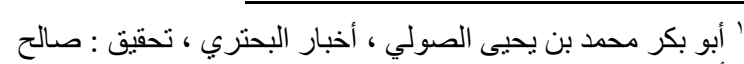

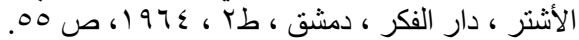

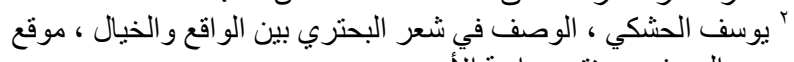

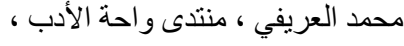
- •-r. ، http://www.3refe.com/vb/showthread.php?t=104064

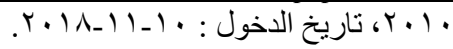


أدار اللوى بين الصريمة والحمى أما للهوى إلا رسيس الجو قصد ؟ بنفسي من عذبـــت نفسي بحبه وإن لـم يكن منـــه وصــال ولا ود

حبيب من الأحباب شطت به النوى وأي حبيب ما أتى دونـــــ البعـــ

يلاحظ بأن البحتري وقف على أطلال المحبوبة (علوة) يبث إليها معاناته كما

وقف شعراء العصر الجاهلي، فهو" يقف بدار العامرية، وهي أطلال دار المحبوبة، حيث الانقطاع والهجر، ذاكرا الربع والأنواء، ودار اللوى، كأنه قائم

$$
\text { في الصحراء "' فراء }
$$

وهذه الأبيات تعمق تجربة البحتري وقد استحضر المكان وتفاصيله من خلال همزة النداء (أطلال،

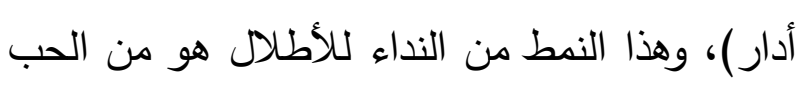
العفيف الذي كان في العصر الأموي، وكأنه يستحضر الموروث العربي القديم الذي يتكرر فيه هذا الحب الطاهر . - ل

يعبر البحتري في هذه الأبيات عن إحساسه باليأس والإحباط وقد استخدم الهمزة لنداء المحبوبة التي لا تغيب عن باله، ويوجه الخطاب إلى أطلال العامرية فهو يحاول نقل معاناته وبث أحزانه وآلامه، إذ يردز في ذلك إلى مكان الأحبة الذي أصبح مهجورا وتحول إلى أطلال وبقايا ذكرى عالقة في ذهن

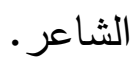
كما يحدد الثاعر الديار المفتقدة وهي (الصريمة، والحمى) وقد لازم وصف الأطلال وصف المحبوبة † خلف الوقيان ، شعر البحتري دراسة فنبة ، المؤسسة العربية للار اسات

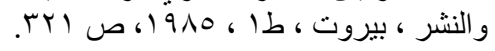

في الأبيات (T (-1))، وهو أيضا يجسد تجربة البحتري الفنية. يقول البحتري في المقطع الأول: سلام عليكم ، لا وفاء ولا عـهـد أما لكم مستسن هجر أحبابكم أكبابنا قـ أنـــز البين وعــده وشيكا ولم ينجز لنا منكم وعد' فالثاعر يتحدث عن مشاعره وإحساسه بالحرقة والأسىى على فراق المحبوبة، ولكنه لا يزال يحمل في قلبه الشعور بالأمل في تراجع المحبوبة عن الهجر والفراق، فهو يعاني من الحزن الثديد بسبب فقدان المحبوبة، وما زال متعلقا بأمل تراجعها عن الفراق و

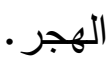
والمرأة التي جاءت في مقدمة البحتري الطللية والتي أحبها بشدة هي علوة التـي تحدث عنها شوقي ضيف بقوله: "إذ نراه ينزل حلب، وهناك تعرف على علوة بنت زريفة التي شغفته حبا، ويبدو أن علوة كانت مغنية، وتعرف أيضا على صديق يسمى الذفافي مدحه ببعض شعره، وهجاه فيما بعد لاقترانه بعلوة، وظلت ذكراها لا تبرح ذاكرة البحتري حتى الأنفاس الأخيرة من يتابع البحتري التعبير عن شوقه وأمله في عودة المحبوبة إذ يقول: أُطـلال دار العامــــرية باللوىى سقت ربعك الأنواء، ما فعلت هند

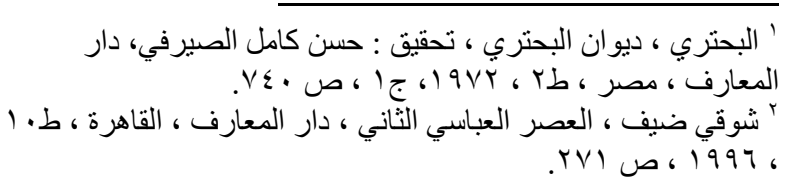


البيت عن وضعها الأصلي الذي هو طلب التصور أو التصديق "' إلى العتاب واللوم الذي يقصد به الأمل في عودة المحبوبة البية والتراجع عن قرارها في البعد. أما البيت الثالث فقد استخدم البحتري الأسلوب الإنشائي وهو النداء في قوله: "أطلال دار العامرية" وهنا قد خرج النداء عن معناه الحقيقي إلى المعنى المجازي وهو عتاب المحبوبة ولومها على الهجر، كما استخدم الثاعر الأطلال للرمز على مكانة المحبوبة وفي الوقت ذاته للتعبير على تجرد الحياة من هذا المكان، كما استخدم الثاعر أسلوب التشخيص في هذا البيت، والتشخيص هو: " الذي

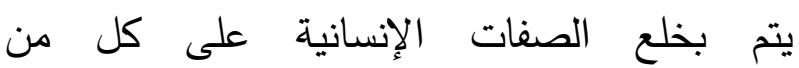
المحسوسات والماديات، أي بخلع صفات الأشخاص الاصل

$$
\text { عليها " باك. }
$$

فقد وجه الخطاب لأطلال دار العامرية وكأنها إنسان يخاطبه ويلومه ويعاتبه، وقد رصد هذا الأسلوب لابه نفسية البحتري حين بدت انفعالاته واضحة وصادقة وهو هنا أسبغ الحياة الإنسانية على بقايا ديار

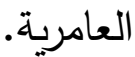

كما استخدم الثاعر الاستفهام بقوله: "ما فعلت هند؟ " فهو يتمسك بمحبوبته ويسأل عنها إذ يقول ما هو اله

مصير هند؟ - مصن

ل السيد أحمد الهاشمي ، جواهر البلاغة ، دار الجيل ، بيروت ، د.ت ،

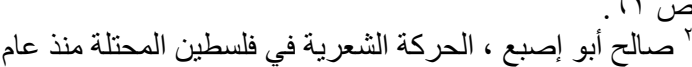

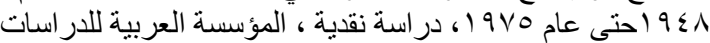

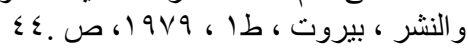

التي صدت الثاعر ولم ترحم معاناته وحرمانه منها، كما أن هذه الدحبوبة تـبتعد عن الثاعر وتحاول

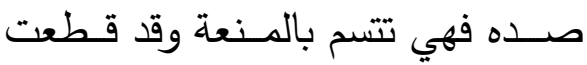
وسيلة الاتصال به، فالثاعر يشكو الصد والهجران

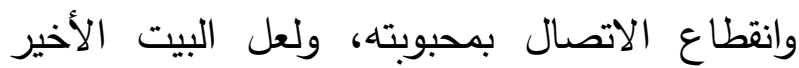
يصور لنا تجربة الثاعر مع الحب، كما أنه يعكس النسال النظرة التشاؤمية للشاعر فهو يقر بأن كل حبيب لابد أن يعاني من ألم البعد والانفصال عن أحبته.

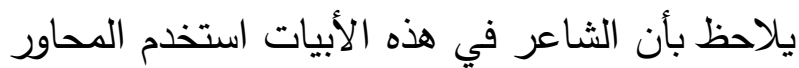
الدلالية والتركيبية والصوتية، ومن الناحية الصوتية اختار البحتري الأصوات التي تتناسب مع النص ولصن الشعري من حيث الثدة والجهر، فقد استخدم حرف اللام الذي تكرر في البيت الأول من القصيدة خمس

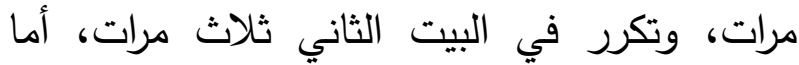
حرف الميم تكرر في البيت الأول خمس مرات، وفي البيت الثاني تكرر مرتين، في حين تكرر حرف الباء في البيتين الأول والثاني ست مرات، إذ يلاحظ بأن

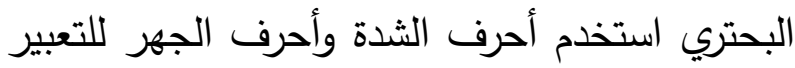
عن قوته وإظهارها في المواقف التي تتطلب ذلك. وعلى المستوى التركيبي استخدم البحتري الهمزة في قوله: "أما لكم" في التعبير عن أمله في عودة لمتئ المحبوبة وتراجعها عن الهجر والفراق، وقد انزاحت الههزة عن معناها الأصلي في هذا البيت إذ يقول الهاشمي: " وقد انزاحت همزة الاستفهام في هذا 
صفات وأخلاق كالسماحة والهدوء، فهو يطلب من

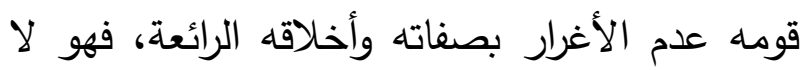
يمتلك نفسه عند الغضب، ويتضح ذلك في قوله : (وإن كان خرقا ما يحل له عقد). استخدم البحتري الأسلوب الإنشائي الطلبي ومن ذلك إنكان استخدم صيغة الأمر بقوله: " فقل" فقد كثف فعل الإنلفئل الأمر عن علاقة الثاعر بأقاربه وهي علاقة يثوبها

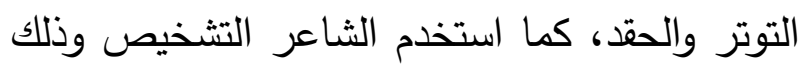
باستدعاء المكان وهو "بطحاء السواجير" فقد أكسب

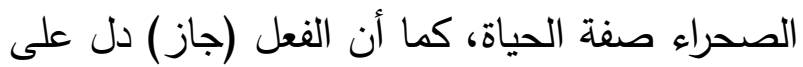
البعد المكاني إضافة إلى البعد الزمني والمسافة التي

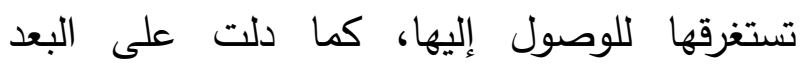

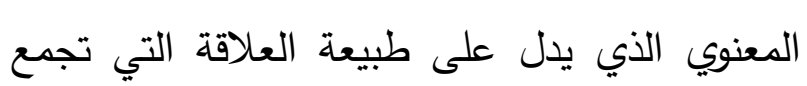
بين البحتري وأقاربه من بني الضحاك. كان لبيئة الصحراء وطبيعتها القاسية دورا كبيرا في ولئي سلوك البحتري ومشاعره و أفكاره وقد جسد ذلك علاقته بأقاربه وانعكس ذلك في قصيدته هذه.

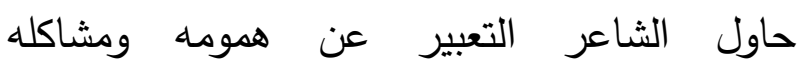
المجتمعة، فقد واجه مواقف عديدة وهي: تخلي المحبوبة عنه، صراعه مع أقاربه وتخليهح عنه، وهو ما دفعه إلى التخلي عنهم واعتزالهم والانصراف إلى الى ونى الصحراء واختيار مواجهة الذئب في الفئي الفيافي والفلوات. كما صور البحتري نفسه بالأفعوان - ذكر الأفعى-، وأيضا صور نفساه بالأسد
كما يعود الثاعر البحتري إلى استخدام هزة الاستقهام في الحديث عن معاناته وإصرار المحبوبة على تعذيبه بالهجر والفراق، لقد لجأ الثاعر إلى المزاوجة بين أسلوب النداء والاستفهام فهو يتحول دالهرب من أسلوب إلى آخر في أجزاء النص وهذا يدل على حالة القلق التي يعيشها الثاعر بسبب هجراه النهر وهدان

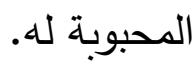
ينتقل البحتري بعد ذلك إلى التعبير عن الفخر والحديث عن ثقته بنفسه في المقطع الثاني فيقول: بلني

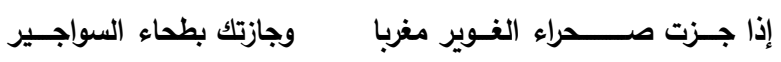

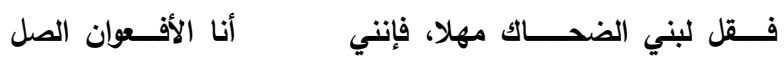
والضيسغ الورد متى هجتموه لا تهيجوا سوى الردى وإن كان خـرقا ما يحسل له عـد' هنترن في هذه الأبيات يوجه الثاعر حديثه إلى شخص يدعى "سعد" وهو الرسول الذي يبعث برسائل

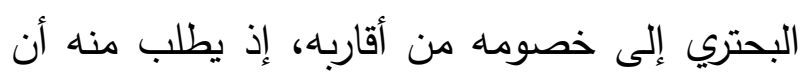

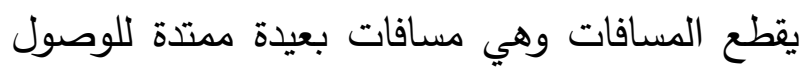
إلى صحراء السواجير؛ لتبليغ رسالته إلى بني الضحاك، وقد وضح في هذا البيت طبيعة العلاقة بينه وبين أقاربه من بني الضحاك ومن ثم يفتخر

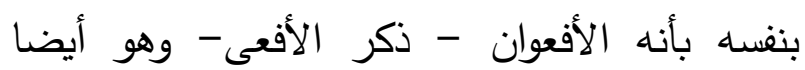
الضيغم و الأسد الواسع الثدق كما أنه في العزيمة كالسيف الحاد القاطع وهذه الصفات يتسم بها لشجاعته وهيبته وإقدامه، ثم يهدد قومه بالموت عند

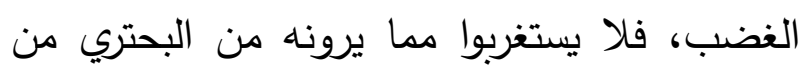


باه بيئتهم، فقد مثلت الطبيعة الجانب الأكثر أهـمية في شعره، وهـذا ليس غريـبا على شاعر يعتبره البعض أحد أعظم الوصافين العرب،

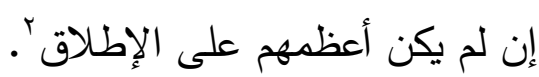
وبعد أن حدد البحتري الزمان والمكان وهو الصحراء وفي هذه اللحظات التي كان الذئب هاجعا غير نائم، ذكر أن كثرة ترحاله وسفره في الصحراء أصبح يثير طيور القطا، كما أن الأفاعي الخبيثة تشعر به، فحركته وخروجه في هذا الوقت تألفه كل الحيوانات إذ تعودت على خروجه في هذا الوقت. لقد تتاول البحتري الزمان والمكان معا وهي الأبعاد الضرورية لتحديد الظاهرة الطبيعة فالجمع بين" الزمان والمكان في تصور واحد يطلق عليه اسم المكان - الزمان (Espace- temps) وهو ذو أربعة أبعاد، تؤلف متصلا مكانيا - زمانيا، يرمز إليه بأربعة متغيرات الطول والعرض والعمق والزمان" '. وقد برزت أهمية المكان بصورة كبيرة في شعر البحتري وهي التي بلورت فكره وثقافته ونظرته " ومن أبلغ آثاره على الكلمات سوى لئي اختلاف معانيها وتتوع مدلولاتها من موضع إلى موضع ما يضفيه على الكلمة الواحدة من لون حسن أو لون قبيح هن دون تأثير كبير في جوهر

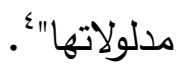

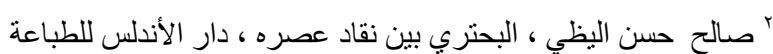

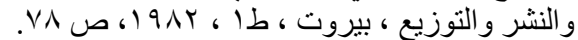

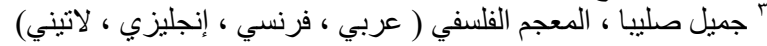

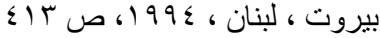

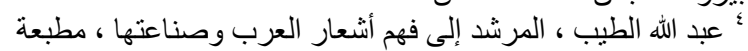

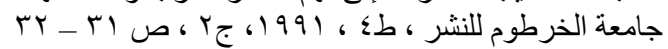

ومن ثم صور نفسه بالسيف الحاد القاطع وهو كناية عن الشجاعة والإقدام والهيبة والرهبة. وينتقل الشاعر لوصف ليلة من الليالي التي عاشها في الصحراء إذ كان يراقبه ذئب جائع في المقطع الثالث فيقول:

وليل كأن الصبــــــع في أخرياته حسشاشة نصل ضـم إفرنده

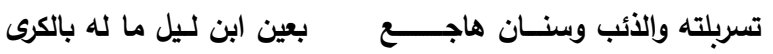
أثير القطا الكرري عن جـــثمانهـ وتألفني فيه الـــثعالب وأطلس مله العين يـــمل زوره وأضلاعه من جانبـيه شوى نها' في هذه الأبيات يحدد البحتري الزمن الذي خرج فيه إلى رحلته وهو أول بزوغ الشمس، حيث كان الضوء كالقطعة الصغيرة التي تظهر من غمد السيف، وفي هذا الوصف دليل على أن الخطر كان يحيط بالبحتري أثناء رحلته، وهو دليل أيضا على قوة البحتري وشجاعته في مواجهة الأخطار، وهي الصورة التي أراد إيصالها لبني الضحاك بالرغم من صلة القرابة التي تربطه بهم، لكن هذه العلاقة بعيدة عن صلة القرابة التي تمثل الأمان والقوة، أنها علاقة تتسم بالعداوة والخصومة. وفي الشعر الجاهلي كان الذئب يشكل نوعا من الصراع مع الإنسان الجاهلي، والبحتري من الثعراء الذين برعوا في ذلك الوصف وتفننوا في نقل ما تموج

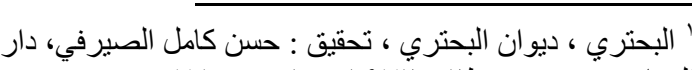

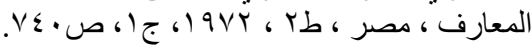


كما استخدم الشاعر أسلوب التقديم أيضا في البيت الثالث فقد قدم المفعول به وهو الضمير المتصل في الفعل (تألفني) ومن ثم جاء بالفاعل وهو (الثعالب) وفي هذا التقديم إثارة للمتلقي وتحفيز له لمعرفة الثيء الذي يألفه الشاعر وتعود عليه في هذه الصحراء القاحلة وفي وقت متأخر يمزج فيه الليل بالصباح، وقد أبدع البحتري في هذا التقديم الذي يثير القارئ ويحفزه لمعرفة باقي الأحداث في القصيدة.

كما استمد الشاعر صورته هذه من الطبيعة، فقد مضى البحتري في رحلته المحفوفة بالمخاطر والحيوانات المفترسة التي تملأ الصحراء فهو بمشيته وخطواته يثير طيور القطا والأفاعي والثعالب، لكن هذه الحيوانات قد اعتادت عليه وألفته وهي صورة من أجمل الصور المستمدة من طبيعة البيئة الصحراوية. استطاع البحتري من خلال استخدامه للفعل ( تألف) سبغ الحياة الإنسانية على الحيوانات، فقد تصرفت كتصرفات البشر بالاعتياد على الشاعر عندما يسافر ليلا وهي صورة نابضة بالحركة والحيوية تعكس قدرات البحتري الإبداعية. كما استخدم الشاعر اللون (أطلس) وهو اللون الأسود المائل إلى الغبرة، ويدل هذا اللون على قوة الذئب ودلالة على شجاعة البحتري في مواجهته لهذا

الذئب.
وعندما بزغت شمس الفجر ، وفي وضح النهار ظهر للبحتري ذنبا لونه أسود مغبر، ويتصف هذا الذئب بالجثة الضخمة، والصدر والأطراف العظيمة، ومن هنا يبدأ البحتري بوصف المعركة التي كانت من

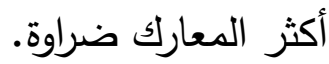
يلاحظ بأن المكان هو المحور في بنية السرد، بحيث لا يوجد قصة أو حكاية بدون مكان، فكل حدث يجب أن يكون له مكان محدد وزمان معين ' ل في البيت الأول من هذه الأبيات قدم البحتري كلمة (إفرنده) وهو المفعول به الذي اتصل به ضمير يعود على الفاعل (غمد) وأراد الشاعر من هذا التقديم التعبير عن انفعالاته والتأكيد على شجاعته وإقدامه في القيام بهذه

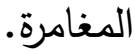
فقد قدم الشاعر المفعول به وأخر الفاعل ليكثف حقيقة المعاناة التي يعيشها فقد ظلمه أقاربه، ولذلك يحاول أن يثبت حقيقة شجاعته وعدم خوفه من الخروج في هذا الوقت الذي يختلط به سواد الليل وظلمته وغبش الفجر وهو وقت الهدوء والسكينة. استخدم البحتري الصورة الفنية فقد شبه الوقت الذي خرج فيه وهو وقت بزوغ الفجر وهو بداية ظهور بياض النهار مع انتهاء سواد الليل، ويقصد بذلك الليل المختلط بالنهار، فهو يثباه هذا الوقت بطرف النصل الذي يظهر من الغمد، وهو من الصور التي برع في وصفها البحتري وأبدع فيها. 
(يقضقض) وهو فعل، وبين (قضقضة) وهي

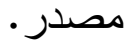

وقد أحدث جناس الاشتقاق في هذه الأبيات نوعا من الإيقاع المنسجم في التماثل الصوتي للحروف، وقد ساهم هذا الجناس في إثراء المعنى وتتوعه، وهو دليل على قدرة الثاعر الإبداعية التي تتمثل في قوته التعبيرية وقدرته على التأثير في المتلقي. كما استخدم الثاعر أسلوب التقسيم في البيت الثالث

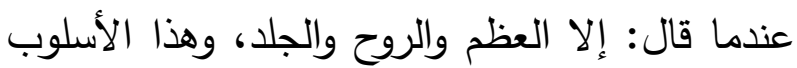
من الأساليب الإبداعية التي تئدي إلى إثارة ذهن المتلقي وتثويقه في إيجاد العلاقة بين أجزاء الكلام

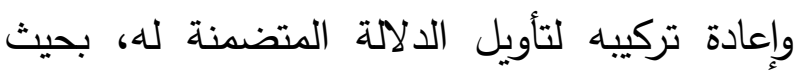
توصل المتلقي إلى نتيجة وهي رسم الملامح العامة للذئب والتي تدل على تشوقه للقتل والدماء وتبرز شراسته واستعداده للقتال. تميزت أبيات البحتري في الجمع بين الأحرف المجهورة والأحرف المهموسة، فقد كانت الأحرف الأب

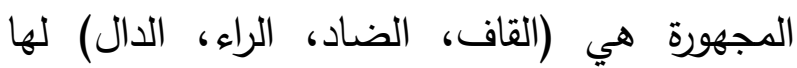
النصيب الأكبر في الأبيات السابقة. أيضا استخدم البحتري التشبيه في البيت الأخير إذ الذبات شبه الذئب واصطكاك أسنانه بالثخص الذي يعاني

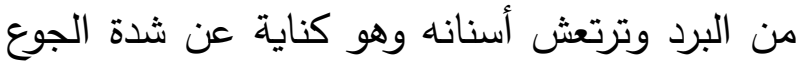
التي ألمت بالذئب، وفي هذا البيت يحاول الثاعر لفت الانتباه إلى أنه سيواجه عدو شرس يعاني من لهن الجوع الثديد وهو دليل على شجاعة البحتري وإقدامه وقدرته على مواجهة خصمه، ويربط ذلك بالمقدمة
رسم أيضا البحتري في هذه القصيدة الصفات العامة للذئب الذي سيواجهه وهذه الصفات هي: الجسد الضخم، الصدر المندفع، الأطراف الكبيرة الضخمة. فها هو يصف شراسة الذئب الذي واجها إذ يقول:

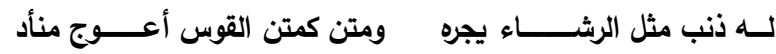

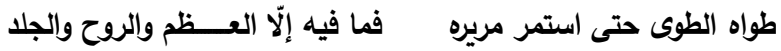

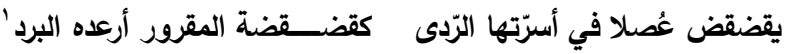
ينتقل الثاعر للحديث عن مشهر مواجهة الذئب، وهي من المواجهات الشرسة التي درات بين الثاعر والذئب، ويوضح أوصاف هذا الذئب وهي: ذو ذنب طويل كالحبل الذي يجره خلفه، وتبدو على ظهره ملامح الاعوجاج الذي يشبه القوس لثدة انحنائه، ثم يصف الجوع المسيطر على الذئب فقد كان بطنه مطوي من شدة الجوع، ومع ذلك سيكون هناك مواجهة تتسم بالقوة والصلابة بين الثاعر والذئب. ولثدة جوع هذا الذئب كان يقارع أسنانه من الجوع لهون كما يقارع المرتجف أسنانه من البرد ويرتعش.

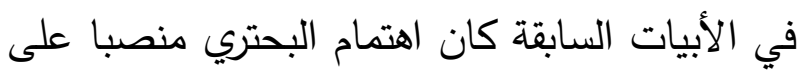
الموسيقى الداخلية، فقد استخدم الإيقاع المتسارع عندما وصف ملامح الذئب المفترس، وابتعد عن الحركات الطويلة التي تساهم في عملية السرد

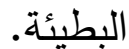
كما استخدم الثاعر الجناس الاشتقاقي في البيت الثاني بين الكلمتين (طواه، الطوى) فلفظة (طواه) فعل بينما لفظة (الطوى) مصدر، وكذلك وردد الجناس الاثتقاقي في البيت الثالث بين كلمتي 
القتل بالسيف، ولشدة ظمأه توهم الذئب بأن الموت سوف يطفأ هذا الظمأ . وفي الأبيات السابقة حاول الشاعر توضيح صورة الذئب المكابر الذي أوهم نفسه بإطفاء ظمأه بالقتل

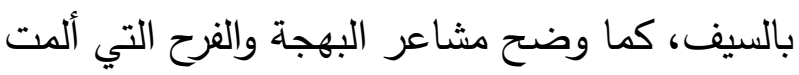
به بعد انتصاره الساحق على هذا الذئب المفترس

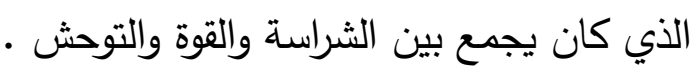
ثالثا: صورة الأئب بين البحتري والمرقش الأكبر وعلاقتها بالأطلال:-

لقد حفل شعر البحتري بالحديث عن الحيوانات المفترسة، التي تمثلت بشتى فنون الثعر الجاهلي بسبب طبيعة الحياة في تلك البيئة الصحراوية فقد تفنن الشعراء في وصف الوحوش من ذئاب وضباع وغيرها بأوصاف متتوعة وهو أمر طبيعي أن يتحدثوا عن هذه الحيوانات؛ لأنهم ألفوها وارتبطوا بها ارتباطا شديدا بحيث لا تخلو أشعارهم من وصفها، ومن ذلك لكان قول المرقش الأكبر في مقدمته الطللية التي صور فيها زيارة الذئب بقوله:

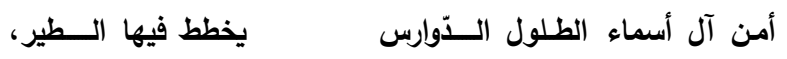

$$
\begin{aligned}
& \text { ذكرت بها أسماء لو أن ولـيهـا }
\end{aligned}
$$

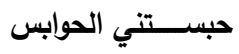

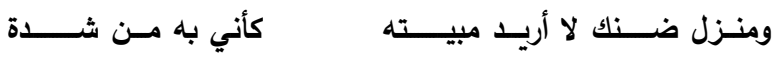$$
\text { الروع آنس فس في }
$$

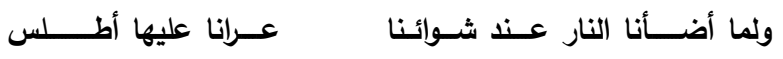

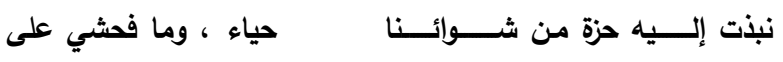
اللون بائس أسن من أجـالس
الطللية التي يواجه فيها بشجاعة آلامه وأحزانه ومعاناته من فقدان محبوبته بعد زيارته إلى مكانها

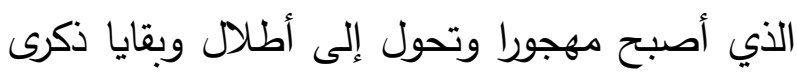
عالقة في ذهن الثاعر . يتابع البحتري وصف الصراع الذي دار بينه وبين

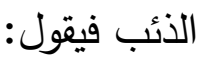

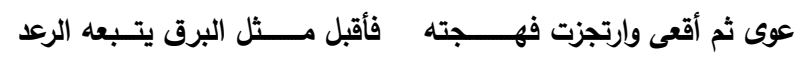
فأوجزته خرقاء تحسـسب ريثها فما ازداد إلا جــــرأة وصـــرامـة وأيــقتت أن الأمر منه هو فخر وقد أوردتـــه منهل الزربى على ظمأ لو أنه عـــنب الورد' يواصل البحتري وصف مشهد المواجهة بينه وبين الذئب إذ يقول عندما شاهد الذئب البحتري بدأ

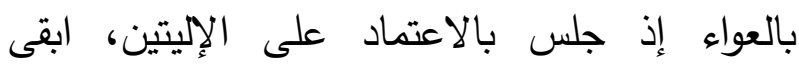
الأماميتين منتصبتين فقام البحتري بزجره، في حين كانت ردة فعل الذئب بالانطلاق نحوه بسرعة البرق، فما كان من الثاعر إلا أن قام برميه بسهام مخترقة نافذة تشبه الريح الهوجاء، وقد واجه الذئب هذه

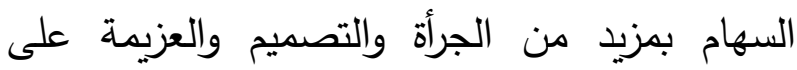
المواجهة، في الوقت الذي كان البحتري يظن ان الذئب سوف يتراجع ويعلن استسلامه، لكن الثاعر أدرك جدية الذئب في القضاء عليه والتخلص منه، فقد أدى اندفاع الذئب نحو الثاعر لقتله وهو يدرك أن الموت ينتظره، فقد عاش الذئب حالة من الحيرة

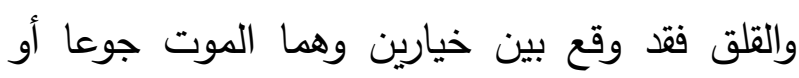


الحبور ، وتعكس هذه الصورة رغبة الشاعر الشديدة في قصد ديار المحبوبة أسماء وهو يأمل باستعادتها والعودة بها فرحا، وقد استعار الشاعر صورة الذئب الذي فرح بقطعة الحزة و أخذها وهو يشعر بالفرح والحبور •

كان الاختلاف أيضا في طريقة تعامل كل من البحتري والمرقش الأكبر مع الذئب، فالبحتري في قصيدته أراد التعبير عن قوته وشراسته وجسد دور المتوحش الذي يبتعد عن إنسانيته فقد واجه عواء، وانقض عليه الذئب انقضاضا سريعا ،بينما كانت ردة فعل الثاعر بأن سدد عليه سهاما فأصاب الذئب في قلبه، وجمع الحصى وقام بشواء الذئب وأكل من لحمه تعبيرا عن انتصاره على هذا الحيوان المفترس، أما المرقش الأكبر فقد أظهر إنسانيته عندما رأى الذئب في حالة سيئة وحزينة، فرمى عليه قطعة من اللحم التي فرح بها وهز رأسه شاكرا معبرا عن سروره، وهنا أراد الثاعر أن يصل إلى مقصده وهو الوصول إلى المحبوبة والتعبير عن فرحته وشكره بالوصول إليها. يكمن التشابه بين البحتري والمرقش الأكبر في عدة

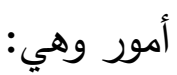
إن البحتري بدأ قصيدته في ذكر أطلال محبوبته علوة والوقوف عليها، وكذلك المرقش الأكبر ذكر ديار محبوبته أسماء لكنه لم يستطع الوقوف طويلا لثدة شوقه وضيقه من غياب المحبوبة، ومن الأمور المتشابهة بين الثاعرين البحتري والمرقش الأكبر هو
فاض بهـا جذلان ينفض رأســهـه كما آب بالنـــــب الكمي

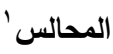
والمرقش الأكبر شــاعر جاهـلي فحل، وقد اشتهر بأنه من عشـاق العـرب و فرسانهم الثجعان، فقد عرف ببأسها وشجاعته وإقدامه في حروبه مع بني تغلب ·. ولقد افتتح قصيدته بالوقوف على أطلال محبوبته أسماء التي أحبها كثيرا وظهر ذلك في أغلب قصائده، وقد غادرت المحبوبة المكان، وتغير حال الشاعر وأحس بالوحشة وقسوة العيش، حتى أنه غادر تلك الأطلال تاركا منزله الذي أحس بأن الحياة فيه لا تطاق فهو يشبه القبر لشدة إحساسه بضيق المكان وقد عكست هذه الأبيات نفسية الشاعر ومشاعره نحو الأطلال نتيجة هجران المحبوبة لهذا المكان، فظهر ذلك واضحا في جميع مقاطع القصيدة. أما صورة الذئب فقد كانت معاكسة لصورة الذئب عند البحتري، فالمرقش الأكبر هجر المكان وانطلق إلى الصحراء فقد نزل عن راحلته وأشعل النار ليبدأ بالشواء، ويظهر ذئب لونه أغبر يميل إلى السواد، وهو ذئب تظهر عليه علامات الحزن والبؤس، وقد أحس الشاعر بحالة هذا الذئب فيستضيفه ويقطع له حزة من شوائه ويرميها إليه ويمسك الذئب بهذه القطعة بشدة ويعود سعيدا بها ويهز رأسه من شدة

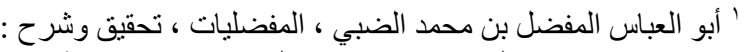

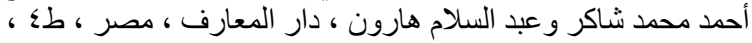

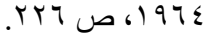

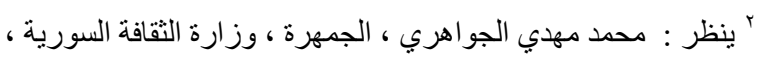

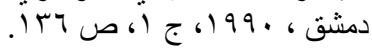


بقوله: " اتسع الوصف في هذا العصر في الطبيعة، في الشعر والنثر، فكثر وصف الرياض، وما فيها من ماء وأثجار وأزهار وأثمار ، وبما يتقلب فيها من ون

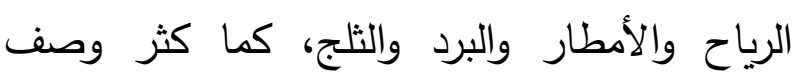
الحيوان والأطيار والوحوش، ولقد رأينا غرضا في في

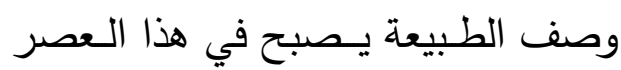
فنا قائما بذاته هو فن الزهـريات " '.

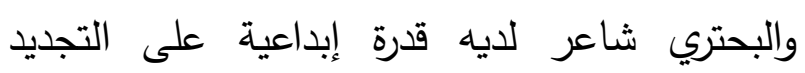
وتداول الصور، فقد كانت الطبيعة الحية مصدر إلهام له لذلك استطاع أن يضعنا أمام مشهد طبيعي يتسم بالدقة في الوصف والتفاصيل. يعلق الدكتور عناد إسماعيل على قصيدة البـحتري لوفي

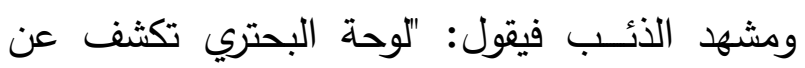
بعض ملامح التغيير الاجتماعي والحضاري الذي لوحيه طرأ على مفهوم الفروسية العربية، فتحول فيها لتهيل

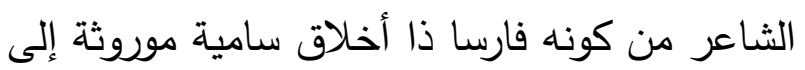

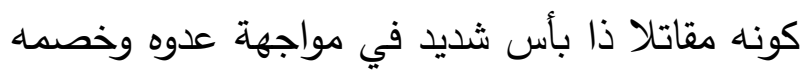

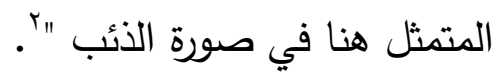
استخدم البحتري في البيت الأول أحرف المد في في ألئ كلمات (عوى، أقعى) وهي أحرف أحدثت إيقاعا متسارعا فالبحتري نقل لنا صورة الذئب في سرعة اعته حركته، فقد استخدم الألفاظ القصيرة الموزونة التي في فئري

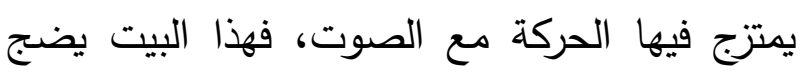
بالحركة والصوت والحيوية، إذ كثف البحتري الفعل

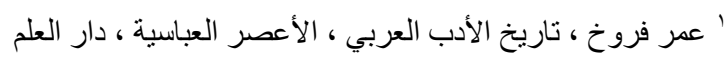

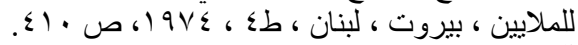

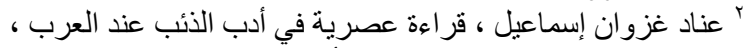

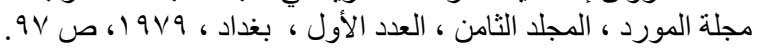

التمهيد لمشهر الذئب، فالبحتري مهر لمشه الذئب، وقد خص الذئب بأبيات شعرية وكان وصفه للذئب

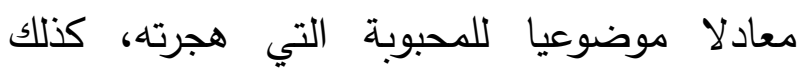
المرقش الأكبر الذي بدأ قصيدته بالحديث عن ديار

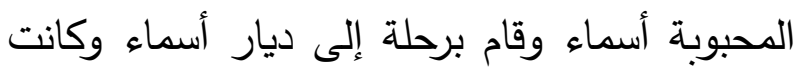

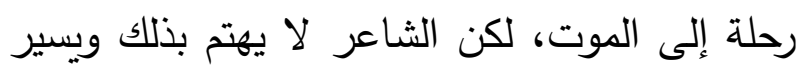
في رحلته مطمئنا قاصدا ديار المحبوبة.

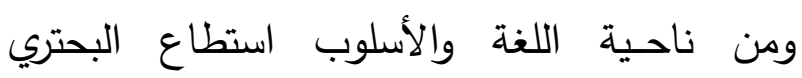
والمرقش الأكبر نــقل أفكارهما باستخدام لغة مكثفة وأسلوب قصصي رائع، وكان استخدامهما لقصة الذئب استخداما موفقا، وكلا الثاعرين شخص الذئب، فالبحتري استعار الذئب

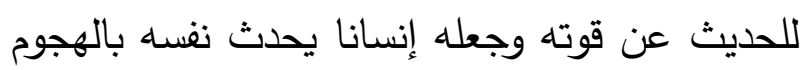

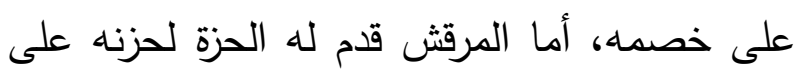
حالته السيئة، فالبحتري عكس صفاته وهي الثراسة والوحشية، أما المرقش فقد عكس إنسانيته وكرمه وعدم بخله في إكرام جليسه.

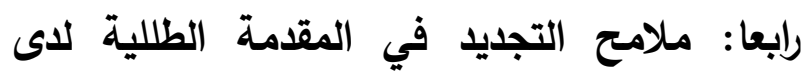

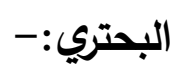
ازدهرت الحياة الأدبية في العصر العباسي وتطورت بشكل كبير، فسار الشعر نتيجة لذلك في تيار

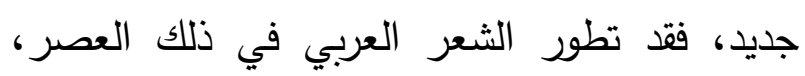

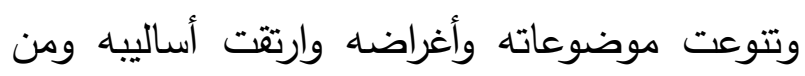

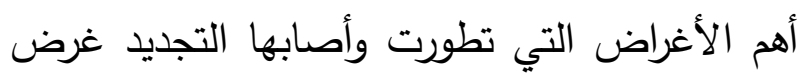
الوصف، الذي امتد ليشمل جميع مناظر الطبيعة ومظاهر الحضارة الحديثة، ويصف عمر الفروخ ذلك لكئك 
وفي البيت الثالث استخدم الثاعر أسلوب القصر لإفادة التوكيد بقوله: فما ازداد إلا جرأة وصرامة، فقد

قصر البحتري صفة الزيادة على الجرأة والصرامة.

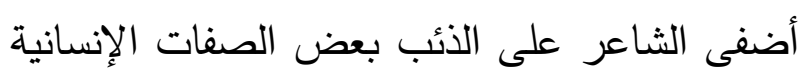

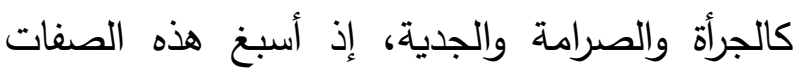

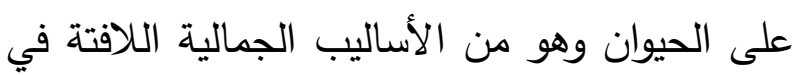
هذه القصيدة. استخدم الثاعر في البيت الرابع جناس الاشتقاق

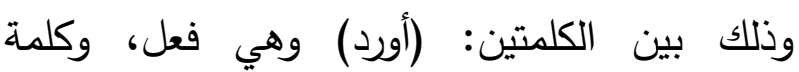

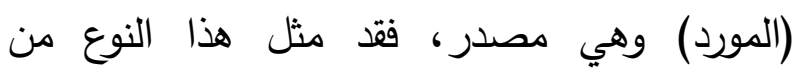
الجناس ملمحا أسلوبيا يؤدي المعنى بعبارة موجزة

ويمنح المتلقي أفاقا رحبة في تخيل دلالة العبارة. كما استخدم الشاعر التشبيه بالمقلوب في البيت الرابع إذ شبه الردى بالمنهل فقد ظهرت القوة والغزارة في كلمة (الردى) أكثر من كلمة (المنهل) وذلك أن بأن

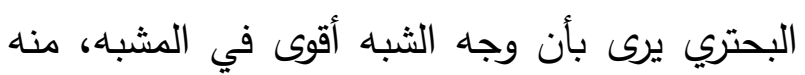

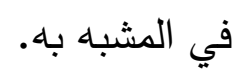
وفي البيت الأخير تتاص البحتري مع البيت الشعري للثاعر عنترة بن شداد وهو:

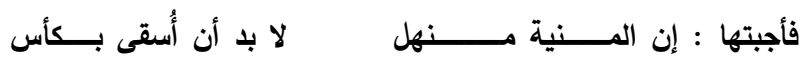
المـنهن : فقد عكس التتاص ثقافة البحتري وتجربته الثعرية الغنية التي حققت الاستجابة الانفعالية عند المتلقي، وجعلته قادرا على تتمية التصورات وتطويرها من التهنيه التعاله صورة إلى أخرى.

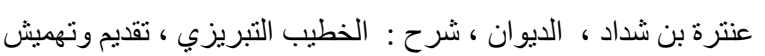

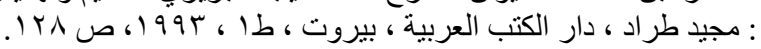

وردة الفعل للذئب عندما واجه الثاعر بكل شراسة وقوة، إذ صور سرعة الذئب وشدة انقضاضه، كما وضح لنا ردة الفعل أيضا وهي الاستعداد للمواجهة، كما استخدم البحتري التشبيه إذ صور اندفاع الذئب نحوه كالبرق الذي يظهر في السماء قبل صوت البتري الرعد، فالذئب هاجم البحتري بسرعة فاقت خروي لهري صوته، وهذا التشبيه جاء بهذه الصورة كناية عن

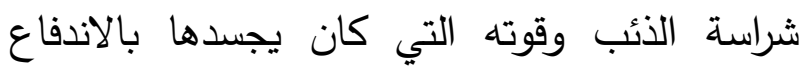
وعدم الاستكانة أو التراجع. وقد جاء هذا البيت نابضا بالحركة، فقد استخدم البحتري العديد من الأفعال الحركية وهي: (عوى، باءلهاء

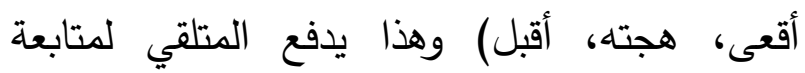

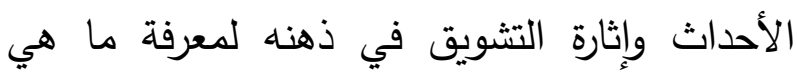
نهاية هذا الذئب الشرس الذي وقع في مواجهة مع الثاعر الذي لا يبالي بقوة هذا الذئب واندفاعه فهو يحمل من الإقدام والثجاعة أضعاف ما يحمله هذا

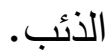

كان لحروف العطف دورا كبيرا في تنظيم وترتيب الأحداث كما كان لها أهمية بالغة في تجسيد الحركة وبعث مشاهد النشاط والحيوية. كما استخدم البحتري أسلوب التقديم في البيت السابق، فقد قدم المفعول باه وهو الضمير المتصل (الهاء) بالفعل ( يتبع) على الفاعل (الرعد). أما البيت الثاني فقد شبه الثاعر السهام التي سددها نحو الذئب بالرياح الخرقاء القوية وهو كناية عن قوة الثاعر وعزيمته وإقدامه وشجاعته. 
تجاوزها إلى إثارة ذهن المتلقي وجعله يعيش معه هذه المراحل الصعبة التي عاشها وتجرعها. تميز مشهد الذئب في قصيدة البحتري باللغة الشعرية الوصفية العالية، وقد زخر المشهد بألوان البلاغة المتنوعة، كما جسدت لنا اللغة الحركية المشهد وكأنه مشهد نراه أمام شاشة السينما، وهو المشهد الذي دفعنا إلى الاقتناع بشجاعة البحتري وجسارته، على

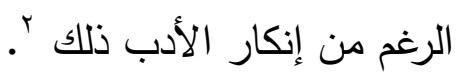
فالبحتري نقل للمتلقي صورة الصحراء التي صرع فيها الذئب، ثم عملية شوائه، ثم تتاول جزءا من لحمه، ثم تركه وانصرف عنه على الرغم من جوعه الشديد، فالخلاصة التي أراد نقلها للمتلقي هي لا يمكن الفرار أو الهروب من مواجهة الصراع في الحياة قبل مجيء الموت׳ّ. يلاحظ في هذه الأبيات براعة الوصف عند البحتري وحسن الديباجة وجمال الإيقاع كما تميز بدقة الوصف الحسي لمظاهر الطبيعة الصامتة والحية فقد تميز الثاعر بقدرته الإبداعية في وصفه واختياره لألفاظه وحسن تصويره ويعد البحتري إماما في الوصف لا سيما وصف الذئب والأسد لكن وصفه وهيل للذئب كان " أكثر دقة وأنشط حركة وأعمق

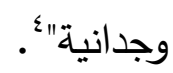

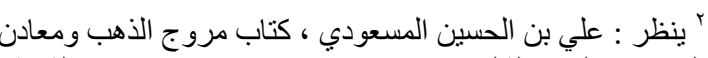

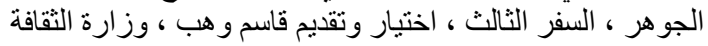

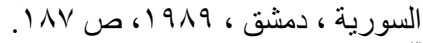

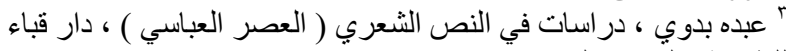

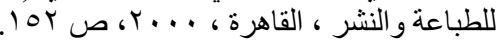
" إيليا سليم حاوي ، فن الوصف في الثي الثعر العربي ، دار الكتاب اللبناني ،
يتابع البحتري وصفه للذئب بقوله: وقتت فجمعت الحصى، واشتويته عليه، وللريـــــاء من تحته وقد ونلت خــسيسا منه ثم تركـته وأقلعت عـــنه وهو منعـقر فرد يتحدث الثاعر عن الموقف الذي صدر منه فقد قام بجمع الحصى وشواء جزء من الذئب، فقد أقدم الشاعر على الأكل من الذئب، فقد حدد المكان الذي أشفى غليله وهو ينظر إلى الجمر واللهر المحيط بجسد الذئب، وهو دلالة على فرح البحتري وبهجته بالنصر على هذا الذئب، وهو تصرف يعكس علاقة البحتري بأقاربـه. أظهر البحتري قسوة البيئة والحياة بأكله جزءا من لحم الذئب، وكأنه أراد أن يظهر قوته وبطشه لأعدائه من أقاربه بني الضحاك، وهو مستعد للقتال والمواجهة، إذ يوجد بداخله ذئب لا يرحم، فهو يحاول تعويض نفسه بهذه القوة والفخر عما لاقاه من أقاربها من عداوة وكراهية. وقد اكتفى الشاعر بأكل القليل من لحم الذئب والانصراف ،ويلاحظ ارتباط الأفعال ببعضها البعض فقد كانت الأفعال متتالية وهي: ( قمت، فجمعت، اشتويت، نلت، تركت، أقلعت) وهي الأفعال التي ساهمت في تسلسل الأحداث وتطورها. لم يكتفِ البحتري باستخدام الصورة والتعبير عن تجربته، وتجريدها وصبها في قالب حسي، بل ' البحتري ، ديوان البحتري ، مصدر سابق ، جr ، ص ع ع V. 
الثاعر الذي استطاع أن يضعنا أمام مشهد

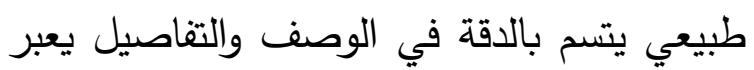
فيه عن معاناته التي تتجسد في اندثار المكان والزمان، وتتنهي بإرادته إذا ابتعد عن مكان الآلام

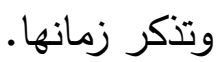

كان لامتزاج الطبيعة في حياة الثاعر دور واضح، فقد ساهدت الطبيعة الصامتة بشكل عام والطبيعة الحية بشكل خاص في تفاعل الثاعر معها تفاعلا عميقا كان له أثر كبير في أسر قلبه، وقد اتضح ذلك من خلال المقدمة الطللية وامتد في القصيدة. من الناحية الصوتية عبرت القافية عن وحدة دلالية خدمت المعنى العام وساهدت في كثف دلالاته والتأكيد على أن الأطلال هواجس مؤلمة تؤثر على فكر الشاعر وأعصابه.

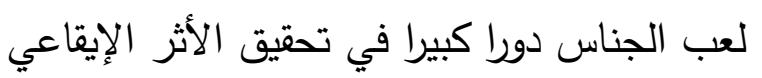
وتوضيح العمق الدلالي لكل كلمتين متجانستين لفظيا. استطاع البحتري الاستفادة من أساليب التصوير كالتشبيه والاستعارة والكناية للتعبير عن تجربته التهري الثعرية والقدرة على التأثير في المتلقي وإقناعه أن الأطلال ألم حارق في الوجدان الإنساني. ارتبطت قصيدة البحتري بالأطلال (آثار الديار)

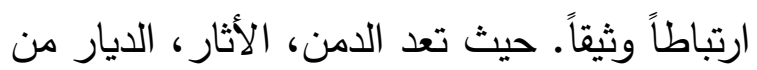

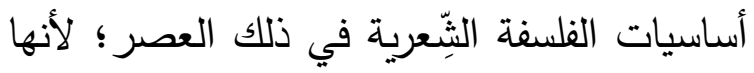

وقد قيل في البحتري: "وصاف ماهر وهو اميل إلى الوصف الحسي الذي يتناول المحسوسات فيبدع في رسمها " ' . وقد أجمع النقاد على أن رشاقة الوصف هي المزية الفنية عند البحتري'، فلم يكن وصف البحتري وصفا عابرا، بل كان يضرب في دقته أروع الأمثلة في

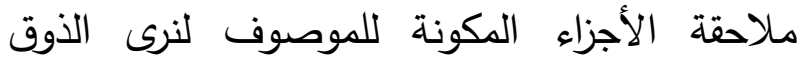
الرفيع والعظمة التي تقف وراء كل ذلك، وهذا

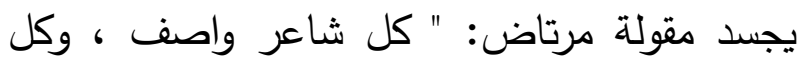

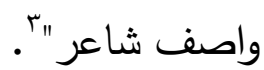
فقد تفنن البحتري في وصف مشهد الذئب بأسلوب

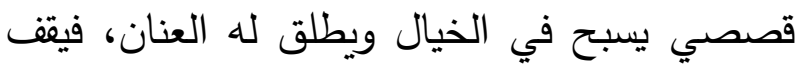
المتلقي عند أسلوبه الإيحائي المبني على لغة لعيط لعيقة الغور تجعل المتلقي يحاول تفكيك أسرارها وتحليلها وتوضيح معانيها الخفية، وعلى الرغم من سهولة ألفاظها الظاهرة، لكنها تحمل في طياتها بنية دلالية للتراكيب تمتلئ بالمعاني العميقة التي يدركها المتلقي في البنية العميقة للغة الشعرية. الخاتمة

تميزت قصيدة البحتري "سلام عليكم" بعدة خصائص منها: قدرة البحتري الإبداعية على التجديد وتداول الصور فقد كانت الطبيعة الحية مصدر إلهام

$$
\begin{aligned}
& \text { ' علي كامل دريب ، لغة الشعر عند البحتري ، رسالة ماجستير ، } \\
& \text {. }
\end{aligned}
$$


- خلف الوقيان، شعر البحتري (دراسة فنية)،

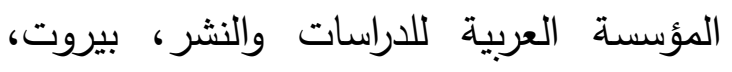

$$
\text { طا، } 910
$$

- ابن خلكان، وفيات الأعيان، دار الكتب العلمية،

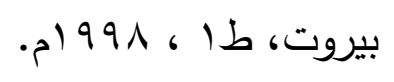

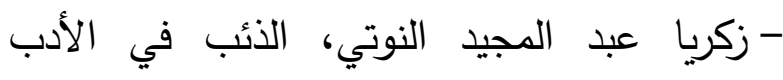

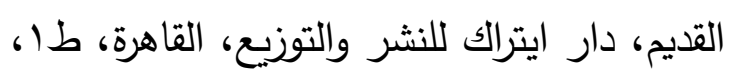

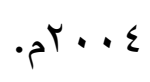

- زهير بن أبي سلمى، الديوان، شرحه وقدم له:

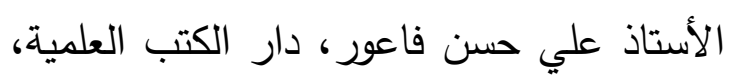

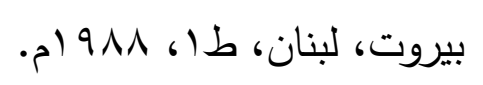

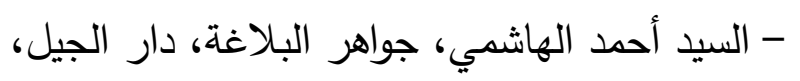

$$
\text { بيروت، د.ت. }
$$

- شوقي ضيف، (العصر العباسي الثاني)، دار

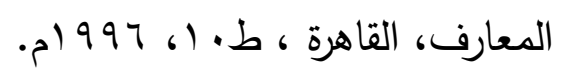

- صالح حسن اليظي، البحتري بين نقاد عصره،

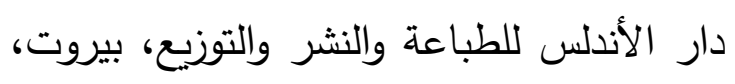

$$
\text { طا، دال }
$$

- صالح أبو إصبح، الحركة الشعرية في فلسطين

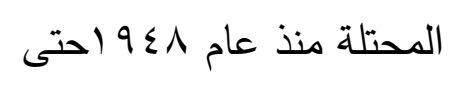

- عام 9 1، (دراسة نقدية)، المؤسسة العبية

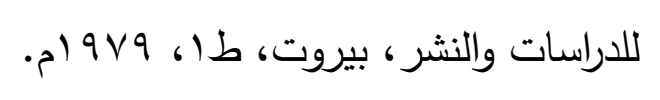

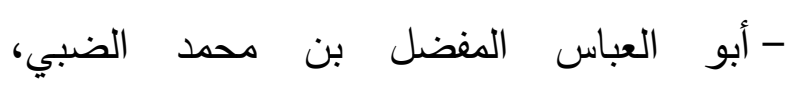

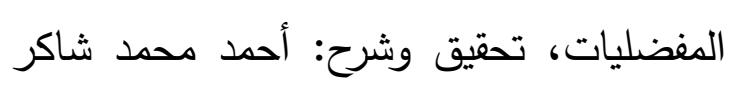

وعبد السلام هارون، دار المعارف، مصر، العثد

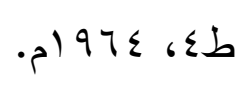

ترمز إلى آثار الأحبة اللذين غابوا بلا عودة

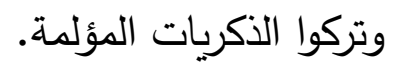

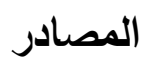

- البحتري، ديوان البحتري، تحقيق: حسن كامل

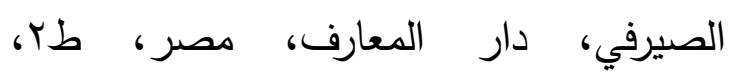
. 9 )

\section{المراجع}

- الآمدي، الموازنة بين الطائين، تحقيق: السيد صقر ، دار المعارف، ذخائر العرب، 970 اموله

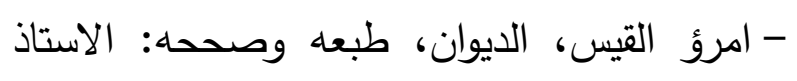

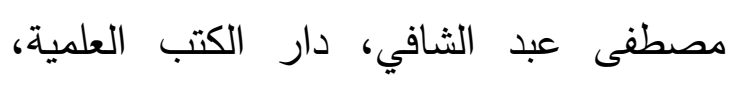
بيروت، لبنان، طه، ع ـ . بrم.

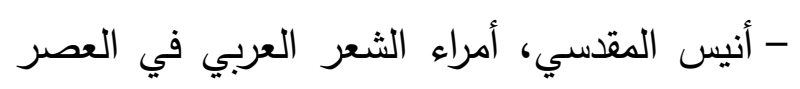

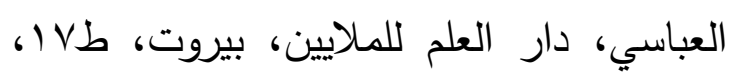

$$
\text { .م) } 919
$$

- إيليا سليم حاوي، فن الوصف في الثعر العربي،

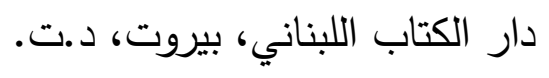

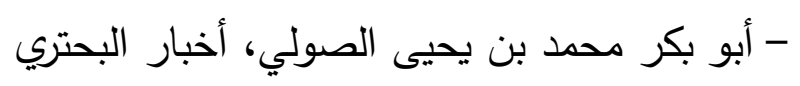

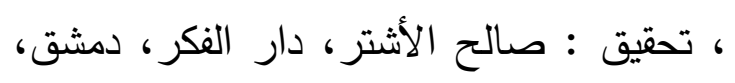

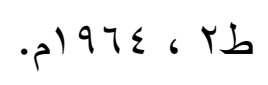

- جميل صليبا، المعجم الفلسفي (عربي، فرنسي،

$$
\text { إنجليزي، لاتيني) بيروت لبنان، } 99 \text { ام. }
$$

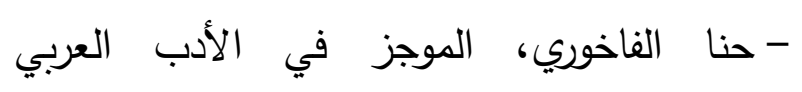

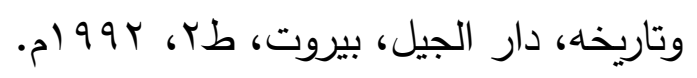


- عنترة بن شداد، الديوان، شرح: الخطيب التبريزي، تقديم وتهميش: مجيد طراد، دار

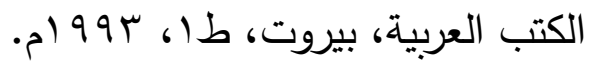

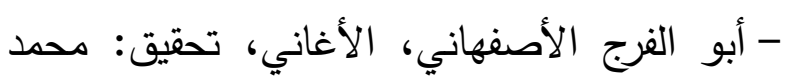

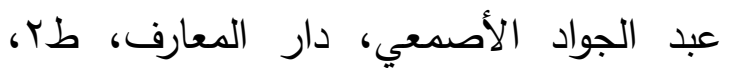
.01901

- محمد بو عزة، تحليل النص السردي (تقنيات

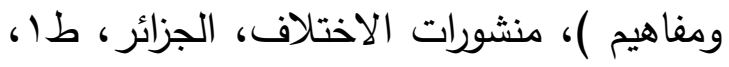
$\cdot r^{2} \cdot 1 \cdot$

- محمد مهدي الجواهري، الجمهرة، وزارة الثقافة السورية، دمشق، · ·99 ام •

- النابغة الذبياني، الديوان، شرح وتقديم: عباس عبد

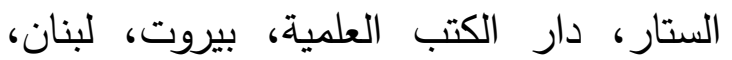

$$
\text { . } 971
$$

- هاشم صالح مناع ، أعلام الفكر العربي، البحتري حياته وشعره، دار الفكر العربي، بيروت، طا،

$$
\text { . }
$$

- ياقوت الحموي، معجم الأدباء، دار المأمون،

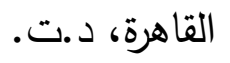

\section{المواقع الإلكترونية}

- يوسف الحشكي، الوصف في شعر البحتري بين الواقع والخيال، موقع محمد العريفي، منتدى

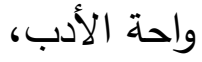

http://www.3refe.com/vb/showthread.php?t=104064 , .30-10-2010
- عبد الله الطيب، المرشد إلى فهم أشعار العرب

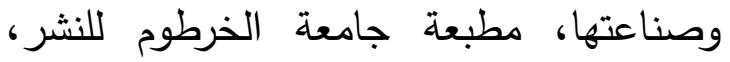

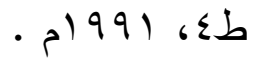
- عبد الله رضوان، البنى الثعرية دراسات تطبيقية في الشعر العربي، عمان، دار اليازوري العلمية للنشر والتوزيع، عمان، 0 . . بم. - عبد الملك مرتاض، الأدب الجزائري القديم (دراسة في الجذور)، الجزائر، 0. . . بم. - عبده بدوي، دراسات في النص الشعري (العصر الجرات

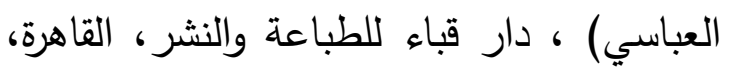
.

- عبيد الأبرص، الديوان، تحقيق: حسين نصار، شركة ومطبعة البابي الحلبي، مصر، لو 90 م. - علي بن الحسين المسعودي، كتاب مروج الذهب ومعادن الجوهر، السفر الثالث، اختيار وتقديم قاسم وهب، وزارة الثقافة السورية، دمشق، - 1919

- علي كامل دريب، لغة الثعر عند البحتري، رسالة ماجستير ، · إ اهـ - .99 ام. - عمر فروخ، تاريخ الأدب العربي، (الأعصر الهر العباسية) ، دار العلم للملايين بيروت، لبنان ، طء، ع \9 ام .

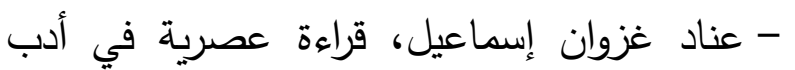
الذئب عند العرب، مجلة المورد، المجلد الثامن،

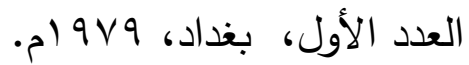




\title{
Description of the ruins in the Abbasid poetry ;poem of "Salamu Alaykum" as an example (Critical study)
}

\author{
Dr. Hamda Mesharik Al- Ruwaili \\ Assistant Professor at the Department of \\ Arabic Language, NBU Univ, Saudia.
}

\begin{abstract}
. he was one of the most famous poets of the description, especially in describing the nature that he loved and tried to employ for his various poetic purposes, so I chose this study On the poem"Peace be upon y " Which is part of this nature, with the aim of shedding light on a text of texts that included a scene from the scenes of the struggle of the Bahtri with the wolf, as this study attempts to identify the technical features in the poetic text and how to deal with it through critical study and disclosure and detect the depth of linguistic connotations and The depths of this poetic text, which carries profound connotations and meanings.
\end{abstract}

key words: Peace be upon you- Introduction to the variant - Features of regeneration - Description of nature. 